\title{
P-36 POTENTIAL HAZARDS CREATES ACTIVITIES OF THE SUBMARINE GAS-HYDRATE BEARING MUD VOLCANOES
}

C.S. MURADOV and R.A. GAVADOVA

Azarbaijan Academy of Sciences, Geology Institute, H. Javid Avenue 29A, 370143 Baku, Azerbaijan

: Mud volcanism is a mighty and one of the most interesting and unusual phenomena in nature. Examination of the geographical distribution shows that, they are found throughout the world and mainly associated with the Alpine- Himalayan and Pacific Ocean mobile belts, in which intense movements of the earth's surface have been observed.

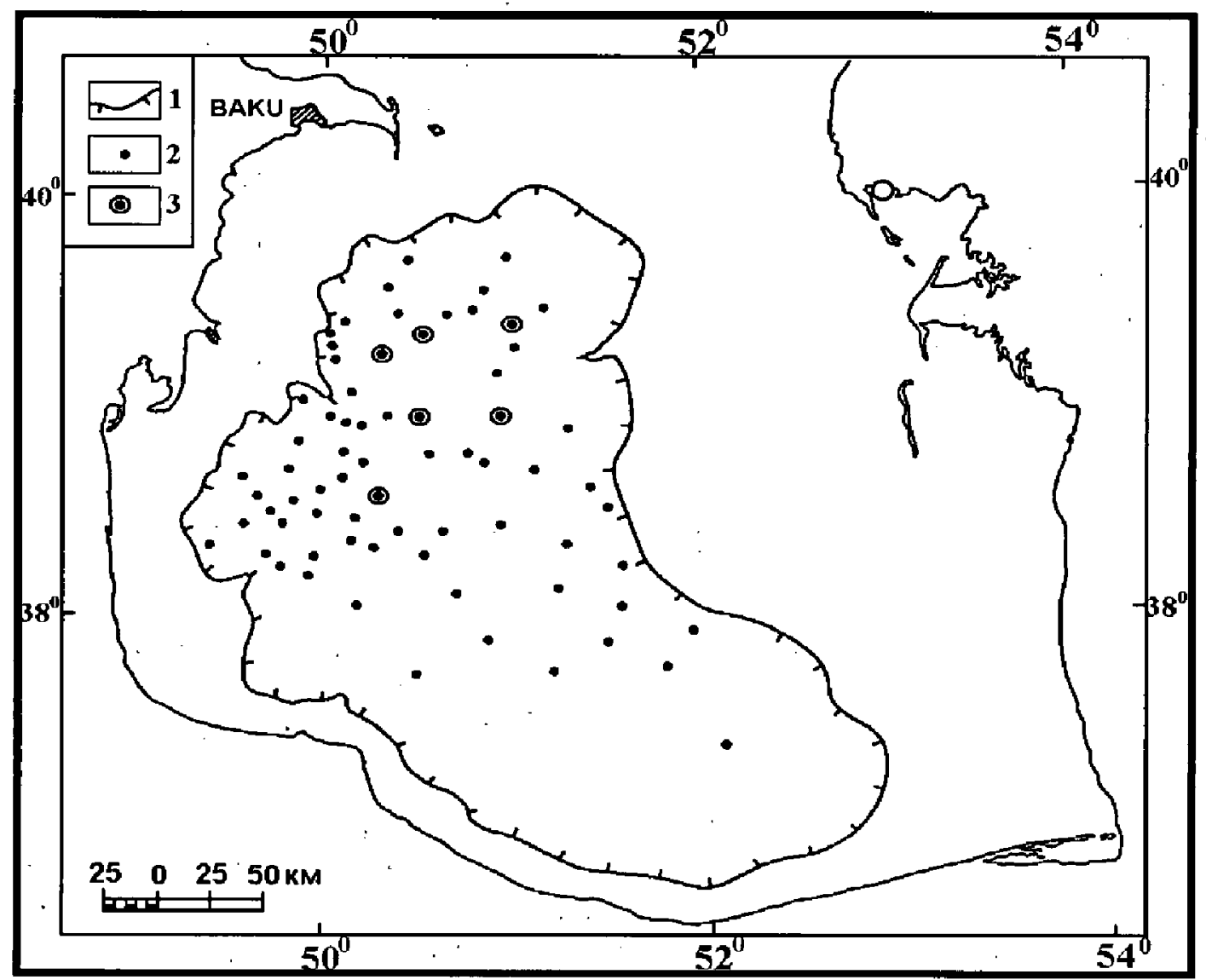

Fig.1. Occurrence of mud volcanoes in the South Caspian

1) Boundaries of gas-hydrate-bearing province; 2) Submarine mud volcanoes;

3) Submarine mud volcanoes with gas-hydrate accumulations 
Mud volcanoes usually form truncated cone from 5 to $500 \mathrm{~m}$ high, but volcanoes which are not known for their powerful eruptions do not usually form distinct topographic highs only 10-20 $\mathrm{m}$, but they often cover an area several kilometers across. The great bulk of the products of mud volcanism are erupted during periodic paroxysmal eruptions. After eruption the breccia undergoes rapid erosion, and the mud flows are reworked into a complex system of gullies and ridges. The greatest volume of gas is given off during paroxysms eruptions of volcanoes. According to assessments made of the basis of duration of combustion and the height of flames during eruption, hundreds of millions of cubic meters of gas are emitted over several hours. The

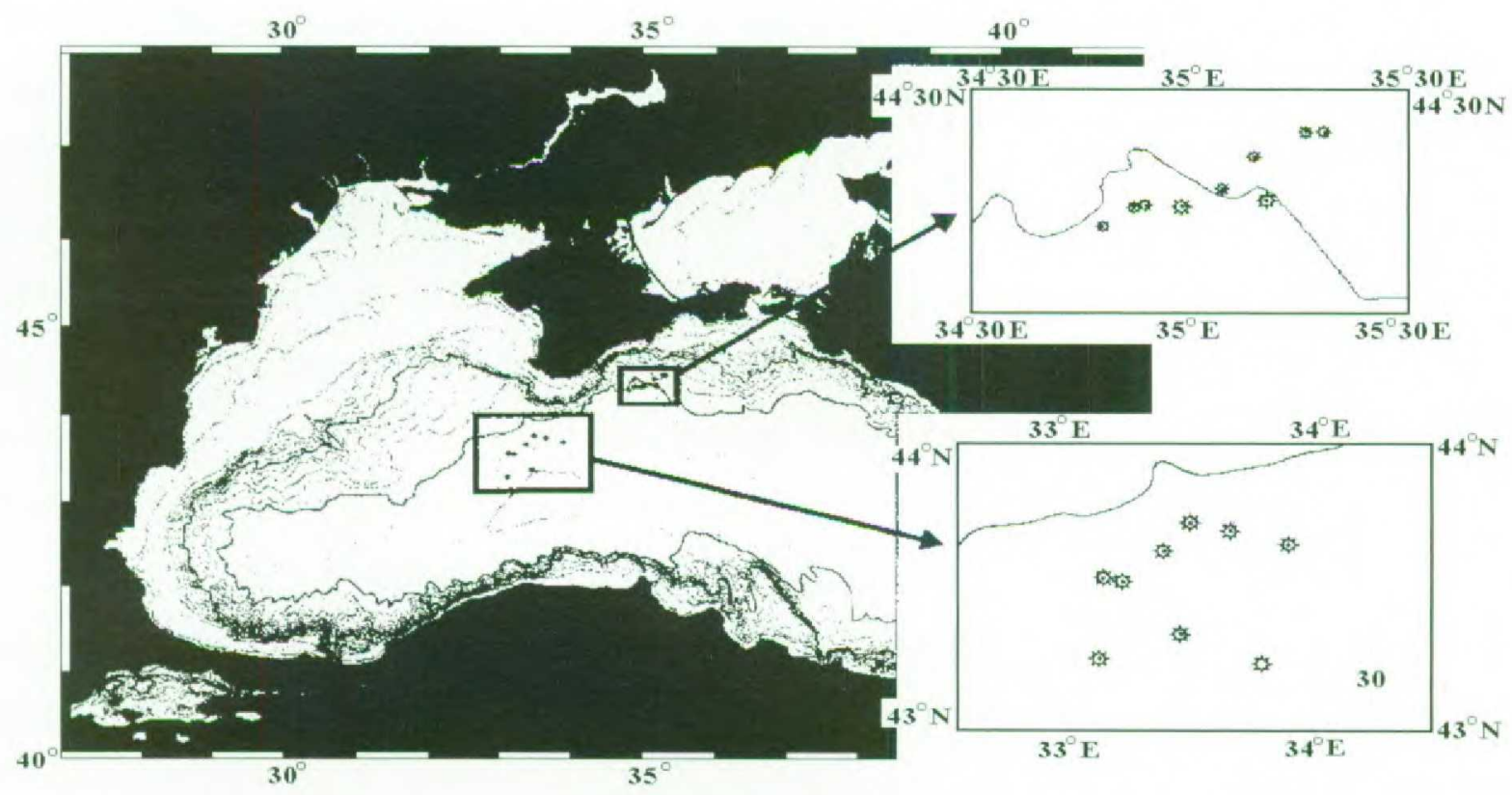

Fig.2. Occurrence of mud volcanoes in the Black Sea

cases are known where eruptions of mud volcanoes have resulted in material damage, and even loss of life both to people and livestock, that is why the majority of active mud volcanoes lie away from centers of population, main routes and technical installations.

Within Alpine-Himalayan mobile belts mud volcanism manifestations are also widespread in the adjacent Seas (Mediterranean, Black, Caspian), for example within the water area of the South Caspian have already been recognized about 150 mud volcanoes. The mud volcanoes of the South Caspian (fig. 1) form permanent or temporary islands and numerous submarine banks, all the islands and banks of the Apsheron and Bakinian archipelagos owe their origin to mud volcanic activity. However, due to irregular wash out by the sea they appear as insular mud volcanoes (with positive mark) or banks. Because of the influence of sea currents, waves and other denuded factors their section rising above the sea level does not exceed $50 \mathrm{~m}$. The regions of the well-developed mud volcanoes in central part of the Black Sea (fig.2) lie within an area 
about $10000 \mathrm{~km}^{2}$, where are recognized 8 largest mud, that have been thoroughly studied, using geological and geophysical methods.

Mud volcanoes of the Mediterranean sea (fig. 3) have been studied not so thoroughly, but is known several submarine mud volcanoes lying on the Mediterranean Sea bed.

Mud volcanoes at sea not only form distinct islands, banks, and submarine mounds, altering the topography and shape of the coastline, but causing local earthquakes and under certain conditions form the hydrocarbon gases in a solid gashydrate state.

Thermodynamic conditions (low temperature and high pressure) are favorable for hydrate formation within the world ocean and it is considered that $90 \%$ of the marine basins correspond to that. An important factor in the formation of accumulations of hydrates of hydrocarbon gases is the submarine mud volcanism, which is the supplier of vast quantities of such gases. The mouths of some volcanoes may, it was thought, form highly favorable sites for the formation of gas hydrates, and the many gas hydrates were discovered within the breccia of the mud volcanoes. Naturally occurring gas hydrates have the potential to store enormous volumes of gas in solid form in ocean-bottom sediments and then to release that gas and water when the hydrates equilibrium conditions are disturbed. Decomposition can be brought about by a drop in pressure or by an increase in temperature, either of which will restore the fluidity of some of the gas and water. On a local scale, this might be caused by drilling or production operations. Natural disturbances of the equilibrium by normal geologic processes are much more widespread. In these cases, release of water and gas from the previously rigid sediment would set the stage for periodic mass movement of sediments, potentially on an enormous scale. The natural elimination of all or part of the zone of hydrate stability could result from any lowering of sea level or from an increase in bottom-water temperature. In the former situation, the hydrostatic pressure decreases and some of the affected would on the amount of lowering of sea level, and hence decrease in hydrostatic pressure.

The name conditions that cause the decomposition of hydrates could also be brought about by continuing sedimentation and deeper burial of the sediments on the slopes. Any hydrate that is formed will be buried ever more deeply under continuing sedimentation. Because of the geothermal gradient and continuing sedimentation, eventually the hydrate will be buried to a depth where it will encounter temperatures at which hydrates are no longer stable. As with sealevel lowering, the bottom layers of the hydrate will melt, and the fluidity of the gas and water will be restored. The same unstable situation will then exist, then mud flows and sediment movement could then be triggered by seismic disturbances. These scenarios present the most 
cataclysmic results of the natural decomposition of hydrates. They certainly would not be expected in every situation where once-hydrated sediments had broken down. Geologic processes of sea-level

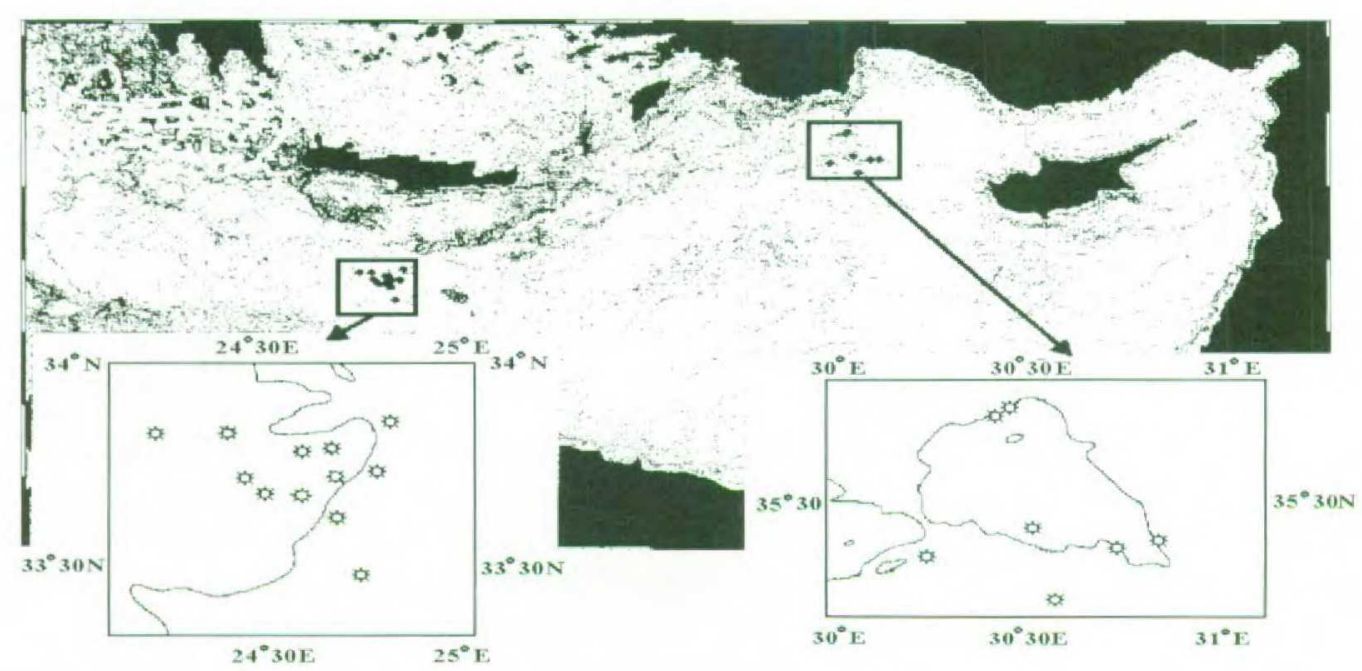

\section{Fig. 3. Occurrence of mud volcanoes in the Mediterranean Sea}

lowering and sedimentation are slow, giving anomalous pressures the opportunity to be dissipated through more permeable zones, fractures, or intermittent small-scale gas release.

A free gas pool accumulating beneath a competent hydrated layer of long duration could also be contained underpressures exceeding hydrostatic. If the hydrate seal for such an accumulation were broken abruptly, the gas along with very fluid gas-cut mud would be ejected. Potentially large volumes of gas, even entire shallow gas fields, would rush to the surface, breaking into smaller and smaller bubbles during its ascent through the water column. If the gas escape were rapid and localized enough, the effect on the surface would be identical with that of a blowout caused by marine drilling operations. There would be a patch of highly agitated frothy water of very low relative density and any vessel accidentally encountering this patch would lose buoyancy and sink quickly. 